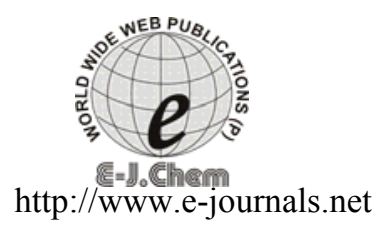

ISSN: 0973-4945; CODEN ECJHAO

E-Journal of Chemistry

2011, 8(S1), S67-S78

\title{
Pretreatment of Palm Oil Mill Effluent (POME) Using Magnetic Chitosan
}

\author{
N. SAIFUDDIN* and S. DINARA \\ ${ }^{*}$ Chemistry Unit, Department of Engineering Sciences \\ College of Engineering, Universiti Tenaga Nasional \\ Jalan IKRAM-UNITEN, 43000 Kajang, Selangor, Malaysia \\ saifuddin@uniten.edu.my
}

Received 10 February 2011; Revised 20 April 2011; Accepted 28 April 2011

\begin{abstract}
Chitosan is a natural organic polyelectrolyte of high molecular weight and charge density; obtained from deacetylation of chitin. This study explored the potential and effectiveness of applying chitosan-magnetite nanocomposite particles as a primary coagulant and flocculent, in comparison with chitosan for pre-treatment of palm oil mill effluent (POME). A series of batch coagulation processes with chitosan-magnetite nanocomposite particles and chitosan under different conditions, i.e. dosage and $\mathrm{pH}$ were conducted, in order to determine their optimum conditions. The performance was assessed in terms of turbidity, total suspended solids (TSS) and chemical oxygen demand (COD) reductions. Chitosan-magnetite particles showed better parameter reductions with much lower dosage consumption, compared to chitosan, even at the original $\mathrm{pH}$ of $\mathrm{POME}$, i.e. 4.5. At $\mathrm{pH} 6$, the optimum chitosan-magnetite dosage of $250 \mathrm{mg} / \mathrm{L}$ was able to reduce turbidity, TSS and COD levels by $98.8 \%, 97.6 \%$ and $62.5 \%$ respectively. At this $\mathrm{pH}$, the coagulation of POME by chitosan-magnetite was brought by the combination of charge neutralization and polymer bridging mechanism. On the other hand, chitosan seems to require much higher dosage, i.e. $370 \mathrm{mg} / \mathrm{L}$ to achieve the best turbidity, TSS and COD reductions, which were $97.7 \%, 91.7 \%$ and $42.70 \%$, respectively. The synergistic effect of cationic character of both the chitosan amino group and the magnetite ion in the pre-treatment process for POME brings about enhanced performance for effective agglomeration, adsorption and coagulation.
\end{abstract}

Keywords: Chitosan, Magnetic chitosan, Coagulation, Palm oil mill effluent (POME)

\section{Introduction}

Oil palm production is a major agricultural industry in Malaysia. The Malaysian palm oil industry is growing rapidly and has become the most the important agriculture-based industry in this country. Malaysia the biggest palm oil producer worldwide ${ }^{1}$ and the total productions of crude palm oil in 2008 and 2009 were 17,734,441 and 16,044,874 tonnes, 
respectively ${ }^{1,2}$. Export earnings from palm oil, palm kernel oil and relating products in 1998 amounted to almost US\$5.6 billion, equivalent to $5.6 \%$ of Malaysia's GDP ${ }^{3}$. The number of palm oil mills in Malaysia has increased tremendously, from about 10 mills in $1960^{4}$ to 410 operated mills in $2008^{2}$. However, the rapid development of the industry has had serious consequences on the natural environment, which mainly related to water pollution due to a large discharge of untreated or partially treated palm oil mill effluent (POME) into watercourses. In 2006, palm oil mills in Malaysia produced more than 58 million tonnes of $\mathrm{POME}^{5}$ and the figure is expected to rise every year. POME is an acidic brownish colloidal suspension characterized by high contents of organics and solids, and is discharged at a temperature of $80-90{ }^{\circ} \mathrm{C}$ (Table 1). It has been estimated that POME contributes to about $30 \%$ of the total biochemical oxygen demand (BOD) load exerted on the Malaysian aquatic environment. Wastewater treatment facility is one of the most important components in the palm oil industry. This facility is normally used to treat a large volume of POME generated during the production of crude palm oil (CPO) before the effluent is safely discharged to the surrounding environment through water canal or river. Specifically, the amount of POME generated is approximately $3.8 \mathrm{~m}^{3}$ for each ton of CPO produced ${ }^{6}$.

Table 1. Characteristics of raw $\mathrm{POME}^{4}$ and the regulatory discharge limits ${ }^{8}$

\begin{tabular}{lcc}
\hline \multicolumn{1}{c}{ Parameter } & $\begin{array}{c}\text { Value, all values, } \\
\text { except } \mathrm{pH} \text { and } \\
\text { temperature, are } \\
\text { expressed in } \mathrm{mg} / \mathrm{L}\end{array}$ & $\begin{array}{c}\text { Regulatory discharge } \\
\text { limit, all values, except } \\
\mathrm{pH} \text { and temperature, are } \\
\text { expressed in } \mathrm{mg} / \mathrm{L}\end{array}$ \\
\hline Temperature, ${ }^{\circ} \mathrm{C}$ & $80-90$ & 45 \\
$\mathrm{pH}$ & 4.7 & $5.0-9.0$ \\
Biochemical Oxygen Demand & 25,000 & $100(50)^{(\mathrm{b})}$ \\
$\left(\mathrm{BOD}_{3}, 3\right.$ days at $30^{\circ} \mathrm{C}^{(\mathrm{a})}$ & 50,000 & - \\
Chemical Oxygen Demand (COD) & 40,000 & - \\
Total Solids (TS) & 18,000 & 400 \\
Total Suspended Solids (TSS) & 34,000 & - \\
Total Volatile Solids (TVS) & 4,000 & 50 \\
Oil And Grease (O\&G) & 35 & $150^{(\mathrm{c})}$ \\
Ammonia-Nitrogen (NH $\left.{ }_{3}-\mathrm{N}\right)$ & 750 & $200^{(\mathrm{c})}$ \\
Total Kjeldahl Nigrogen (TKN) & & \\
\hline
\end{tabular}

(a) Statutory incubation conditions, (b) This additional limit is the arithmetic mean value determined on the basis of a minimum of four samples taken at least once a week for four weeks consecutively (c) Value of filtered sample

Considering the high organic character of POME, the most common practice for POME treatment is by anaerobic-aerobic open ponding ${ }^{4}$ and/or open digesting tank systems ${ }^{7}$; whereby the anaerobic processes provide partial removal of organic matter before further treatment with aerobic processes. The problems associated with treatment of POME using a pond system are long retention time (90-120 days), large area requirement, high demand for maintenance, loss of nutrition and high emission of green house gases (methane and carbon dioxide) from these systems to the atmosphere ${ }^{7}$. Anaerobic biological treatment systems need proper maintenance and monitoring as the processes rely solely on microorganisms to break down the pollutants. There are many palm oil mills, which failed to comply with the Department of Environment (DOE) standard discharge limits even though they have applied biological treatment system in their mills due to very high organic load of the POME. It was reported that the chemical coagulation is the fastest way to reduce the organic load of the 
POME to an acceptable and economical level. Thereby it can be treated using conventional treatment systems ${ }^{9}$. With the increased worldwide concern on environmentally friendly production processes particularly the emission of methane, it is important to develop an alternative concept for POME treatment. Therefore, the pre-treatment of POME using coagulation and flocculation processes has become an important feature, in order to efficiently reduce the organic load prior to subsequent treatment processes. Aluminium sulphate (alum), an inorganic salt, is the most widely used coagulant in wastewater treatment, due to its proven performance, cost-effectiveness and availability. Aluminium sulphate (alum), an inorganic salt, is the most widely used coagulant in wastewater treatment, due to its proven performance, cost-effectiveness and availability. However, the usage of this coagulant has been raised serious health and environment concerns. These coagulants create hazardous activated sludge which contains residual aluminium which may cause side effects when discharged into the open water course. Coagulation-flocculation treatment employing an environmental friendly coagulant could lead to improved effluent treatment as well as gaining benefits through the recovery and recycling of water to the plant with minimum treatment. Natural organic coagulants have been studied as environmental friendly coagulants in recent years in water and wastewater treatment ${ }^{10-13}$.

Chitosan, known as poly[ $\beta$ - $(1 \rightarrow 4)$-2-amino-2-deoxy- $D$-glucopyranose $]$, is a cellulose like biopolymer of high molecular weight obtained from deacetylation of chitin. Chitin, a linear chain polysaccarides, is the second most abundant organic material after cellulose. Besides the reactive primary and secondary hydroxyl groups, chitosan's versatility as an adsorbent is a function of its highly reactive amino group at the $\mathrm{C}(2)$ position ${ }^{14}$. The protonation of the chitosan amino groups $\left(\mathrm{NH}_{2}\right)$ in solution makes the chitosan positively charged (exhibit as cationic polyelectrolytes) and thereby very attractive for flocculation and different kind of binding application. Chitosan offers a broad range of applications favoured by unique properties of chitin and chitosan, such as biocompatibility, biodegradation, biological activity, non-toxicity, non-allergenic and ability for fibre and film formation. In water and wastewater treatment applications, chitosan has been used to synthesize membrane, used as an absorbent as well as primary coagulant or flocculent. It has been proved that chitosan could coagulate and flocculate a variety of suspensions or wastewaters including mash wastewater of brewery ${ }^{15}$. These products must be dissolved, for instance, in acetic acid and can therefore, be applied only within a small range of $\mathrm{pH}$ (up to about 7). Two types of modifications are commonly adopted for the preparation of chitosan based sorbents. Cross-linking to improve its solubility and engineering properties and grafting of functional groups for enhancing the adsorption capacity and/or selectivity.

With the rapid development of nanotechnology, magnetic nanoparticles are currently being widely studied in water treatment field. It is believed that magnetic nanoparticles $\left(\mathrm{Fe}_{3} \mathrm{O}_{4}\right)$ show the finite-size effect and high ratio of surface-to-volume, resulting in a higher adsorption capacity ${ }^{16}$. In addition, easy separation of loaded magnetic nanoparticles from solution and fast settling velocity can be achieved using an external magnetic field. Magnetic particles can be used to adsorb contaminants from aqueous or gaseous effluents and after adsorption, can be separated from the medium by simple magnetic process. However, all these materials have the drawback of a small surface area or a small adsorption capacity, which limits their application. In this work, high surface area and high adsorption capacity and magnetic composites based on chitosan particles/iron oxide nanoparticles were prepared by simple method and used for the removal of contaminants from aqueous effluents. There have been many reports on magnetic $\mathrm{Fe}_{3} \mathrm{O}_{4}$ particles coating with organic 
materials as adsorbent for metal removal ${ }^{17,18}$. However, few studies have been conducted on the composition of magnetic nanoparticles and coagulant solution to enhance coagulation by the adsorption and magnetic effect of $\mathrm{Fe}_{3} \mathrm{O}_{4}$ nanoparticles. In this paper, a novel composite coagulant for pre-treatment of $\mathrm{POME}$ was prepared by adding magnetic $\mathrm{Fe}_{3} \mathrm{O}_{4}$ nanoparticles to chitosan. The high content of amino groups in chitosan also makes possible many chemical modifications in polymer with the purpose of improving selectivity and adsorption capacity. These nanocomposite beads can be removed easily from water with the help of an external magnet thanks to their exceptional magnetic properties. The coagulation behaviours of chitosan and chitosan-magnetite nanoparticles were studied under different initial $\mathrm{pH}$ conditions and coagulant dosages.

In this paper, magnetic chitosan beads were prepared by a chemical conversion method and the effect of chitosan-magnetite nanoparticles as a coagulant for pre-treatment of POME was assessed. Experiments were done in a series of batch coagulation test to obtain the optimum dosage of coagulants needed to achieve maximum reduction in total suspended solid (TSS), residual oil content, chemical oxygen demand (COD) and turbidity. The coagulation behaviours of chitosan and chitosan-magnetite nanoparticles were studied under different initial $\mathrm{pH}$ conditions and coagulant dosages. These nanocomposite magnetic beads can be removed easily from water with the help of an external magnet due to their exceptional magnetic properties and therefore improves the efficiency of removal of the floc from the POME. Thus, the pre-treatment of POME could be improved in a more economically and environmentally manner.

\section{Experimental}

The waste water from the palm oil mill known as palm oil mill effluent (POME) was obtained from Seri Ulu Langat Palm Oil Mill Sdn. Bhd., in Dengkil, Selangor. The fresh POME collected from the mill was collected at a temperature ranging from 75 to $90^{\circ} \mathrm{C}$. The samples were allowed to cool to around $45-50{ }^{\circ} \mathrm{C}$ before being transferred into plastic container. The containers were sealed tight and labelled before being transported to the UNITEN laboratory. In the lab, the samples were stored at $4{ }^{\circ} \mathrm{C}$ in tightly closed plastic containers until used in order to prevent the wastewater from undergoing biodegradation due to microbial action. Raw POME is a brown coloured suspension, which is slightly acidic and consists mainly of water. POME characteristics vary depending upon the time of sample withdrawal. This might be due to the method of the processing, the quality of the fresh fruits and the time of the collection of the POME. In order to minimize the effect of different characteristics of POME, the experiments were repeated with different samples of POME to obtain the average results. Portions of these samples were withdrawn and analyzed for their initial residue oil content, turbidity, TSS, COD and $\mathrm{pH}$ properties.

Chitosan (medium molecular weight) was purchased from Aldrich Chemical Company, USA. As a flaked material, with a deacetylation percentage of approximate $90 \%$ and an average molecular weight of $3.2 \times 10^{5}$. Iron(II) chloride tetrahydrate $\left(\mathrm{FeCl}_{2} \cdot 4 \mathrm{H}_{2} \mathrm{O}\right)$ and iron(III) chloride hexahydrate $\left(\mathrm{FeCl}_{3} \cdot 6 \mathrm{H}_{2} \mathrm{O}\right)$ were purchased Sigma-Aldrich, USA. All other reagents used were of analytical-reagent grade and used as received. Ultrapure deionized water was obtained using the ELGA Lab Water (UK) water purification system in our laboratory and was used to prepare all the solutions.

\section{Preparation chitosan particles}

Chitosan solution was prepared by $2.0 \mathrm{~g}$ chitosan dissolved in $100 \mathrm{~mL}, 5 \%(\mathrm{v} / \mathrm{v})$ acetic acid solution. The viscous solution was well stirred and left overnight before adding the solution drop wise through a seven-gauge needle into $2.0 \mathrm{M}$ sodium hydroxide solution. This process 
was accomplished by using a model 100 push-pull syringe pump. The formed chitosan beads were kept in the sodium hydroxide solution for 24 hours and washed with distilled water until the washing solution became neutral.

\section{Preparation of magnetite nanoparticles}

Magnetite $\left(\mathrm{Fe}_{3} \mathrm{O}_{4}\right)$ nanoparticles were prepared by co-precipitation using pluronic F127 as a non-ionic surfactant. Deoxygenated ultra pure water was prepared by bubbling nitrogen gas for $1 \mathrm{~h}$ and was used in the preparation of the magnetite particles. $\mathrm{FeCl}_{3} \cdot 6 \mathrm{H}_{2} \mathrm{O}(0.0551 \mathrm{~mol})$ dissolved in $84 \mathrm{~mL}$ of deoxygenated water was mixed with $36 \mathrm{~mL}$ of aqueous solution of pluronic $\mathrm{F} 127(2 \%) . \quad \mathrm{FeCl}_{2} \cdot 4 \mathrm{H}_{2} \mathrm{O}(0.0275 \mathrm{~mol})$ dissolved in $84 \mathrm{~mL}$ of deoxygenated water was mixed with $36 \mathrm{~mL}$ of $2 \%$ surfactant solution. Both solutions were mixed and stirred under strong ultrasonic agitation while heating the solution to $65^{\circ} \mathrm{C}$ for $5 \mathrm{~min}$ and bubbling $\mathrm{N}_{2}$ gas. A sodium hydroxide aqueous solution (12.8 g in $120 \mathrm{~mL}$ of deoxygenated water) was then added using a peristaltic pump with flow rate of $10 \mathrm{~mL} / \mathrm{min}$ while agitating at $65{ }^{\circ} \mathrm{C}$. The reaction was continued for $30 \mathrm{~min}$ under the same conditions. The resulting $\mathrm{Fe}_{3} \mathrm{O}_{4}$ particles were washed repeatedly with distilled water until neutral $\mathrm{pH}$. The solid content $(\mathrm{w} / \mathrm{w})$ was determined for the final suspension by drying an aliquot.

\section{Preparation of chitosan-magnetite nanocomposite particles}

The magnetite nanoparticles obtained in the previous step were covered with a layer of chitosan by ionotropic gelation using sodium tripolyphosphate (STPP) as a cross linking agent.

The magnetite suspension ( $12 \mathrm{~mL}$, solid content $1.245 \% \mathrm{w} / \mathrm{w})$ was first mixed with $11 \mathrm{~mL}$ of surfactant solution and re-dispersed using an ultrasonic bath for $5 \mathrm{~min}$, and then placed in the flask. After that $75 \mathrm{~mL}$ of chitosan solution ( $2 \%$ chitosan in $5 \%$ acetic acid) was added and the reaction mixture was stirred for half an hour. Freshly prepared crosslinker solution ( $140 \mathrm{~mL}$ of aqueous STPP, $0.15 \% \mathrm{w} / \mathrm{w}, \mathrm{pH}=9.6$ ) was then added using the peristaltic pump $(10 \mathrm{~mL} / \mathrm{min})$. After continuing the reaction for $1 \mathrm{~h}$ at room temperature, the mixture was placed in the fridge and left to mature overnight. The resulting particles were magnetically separated the next day and washed 4 times with $500 \mathrm{~mL}$ of distilled water each. After the final wash, the suspension volume was adjusted to $50 \mathrm{~mL}$.

\section{Coagulation jar-test experiments}

The coagulation experiments were carried out by using a jar-test apparatus with six paddles. The POME samples were mix homogeneously before fractionated into beakers containing $500 \mathrm{~mL}$ of suspension each. Prior to the test, the samples were measured for turbidity, TSS and COD for representing an initial concentration. All tests were performed at an ambient temperature in the range of $24-28{ }^{\circ} \mathrm{C}$. The coagulant Jar test was performed using chitosan particles and chitosan-magnetite nanocomposite particles as coagulant. After the desired amount of coagulant was added to the suspension, the beakers were agitated at various mixing times and speeds, which consist of rapid mixing $(250 \mathrm{rpm})$ for 3 minutes and slow mixing $(30 \mathrm{rpm})$ for 30 minutes. After $60 \mathrm{~min}$ of quiescent settling under an external magnetic field, samples were collected at $2 \mathrm{~cm}$ beneath the surface for water for turbidity, TSS, COD and residue oil content measurements, representing the final concentration. The chitosan and chitosan-magnetite nanocomposite particles efficiency was investigated in terms of TSS, COD, turbidity, residual oil removal by the doses in the range of $40-600 \mathrm{mgL}^{-1}$. The effect of $\mathrm{pH}$ was studied in the range of 4-9 and was conducted by adjusting the $\mathrm{pH}$ from 4 to 9 , using the optimized dosage of each coagulant. The $\mathrm{pH}$ was controlled by adding either strong acid $(5 \mathrm{M} \mathrm{HCl})$ or strong base $(5 \mathrm{M} \mathrm{NaOH})$. 


\section{Analytical analysis}

Turbidity was measured using HACH Ratio/XR turbiditimeter (HACH Company, USA). The measurement is based on the light-transmitting properties of water. A gravimetric method was used to determine the TSS, with the aid of vacuum filtration apparatus. The weight of solids retained on a filter paper was determined after heating. The total suspended solid removal percentage was calculated as follow:

$$
\frac{S S_{\text {raw POME }}-S S_{\text {aftertretment }}}{S S_{\text {raw POME }}} \times 100 \%
$$

The COD test was performed by colorimetric method using spectrophotometer Shimadzu Model DR/2000. It measures the amount of oxygen $\left(\mathrm{O}_{2}\right)$ required for complete oxidation of organic matter using strong oxidation agent, i.e. dichromate ion $\left(\mathrm{Cr}_{2} \mathrm{O}_{7}^{2-}\right)$. COD reduction percentage was calculated as follow:

$$
\frac{C O D_{\text {raw } P O M E}-C O D_{\text {affertretment }}}{C O D_{\text {raw POME }}} \times 100 \%
$$

Particle zeta-potential, $\xi$, was measured in phosphate buffer $(\mathrm{pH}=6)$ on a Malvern Zetasizer ZS90 system. The residue oil content was measured using the oil and grease method recommended by APHA Standard Method of Examination of Water and wastewater ${ }^{19}$, with $n$-hexane being used as the oil-extraction solvent. The turbidity, TSS, COD and oil content was determined for each sample of POME both before and after experiment. Three replicates of each test were undertaken with the mean value obtained for residual oil content being calculated from the replicates. All tests were carried out at an ambient temperature of $24-28{ }^{\circ} \mathrm{C}$. The concentration of residual oil was estimated as follows:

The original and treated POME samples were transferred to a separating funnel. Thirty $\mathrm{mL}$ of petroleum ether were introduced into the separating funnel. The contents were shaken vigorously for $2 \mathrm{~min}$ and allowed to separate into layers for $5 \mathrm{~min}$. The aqueous layer was drip drained into a sample holder. Extraction was repeated twice with two more portions of $30 \mathrm{~mL}$ petroleum ether. Then, the solvent layer was drained through a funnel containing filter paper and $2 \mathrm{~g}$ of anhydrous sodium sulphate, both of which had been solvent-rinsed, into a sample holder. The sample of extracted residual oil with petroleum ether was used for the analysis.

The concentration of residual oil extracted with petroleum ether was then measured using a spectrophotometer with an absorbance wavelength of $444 \mathrm{~nm}$. A calibration with different concentrations of residual oil versus absorbance was done. Hence, using this calibration curve the concentrations of residual oil before and after adsorption were calculated.

\section{Results and Discussion}

\section{Characteristic of Raw POME}

The Table 2 list the values for the tested parameters of POME sample before the coagulation pre-treatment. The values are within the range of the expected values based on previous result ${ }^{4}$. 
Table 2. Values of selected parameters of raw POME

\begin{tabular}{cc}
\hline Parameters & Raw POME \\
\hline $\mathrm{pH}$ & $4.3-5.1$ \\
Oil and grease & $4500-5500 \mathrm{mg} / \mathrm{L}$ \\
COD & $43000-51000 \mathrm{mg} / \mathrm{L}$ \\
TSS & $15000-20000 \mathrm{mg} / \mathrm{L}$ \\
Turbidity & 11613 \\
\hline
\end{tabular}

Surface property of magnetite and chitosan-magnetite nanocomposite particles

The results of $\zeta$-potential measurement is presented in Table 3. Magnetite particles are negatively charged at $\mathrm{pH} 7.0$ due the presence of adsorbed hydroxyl ions. After chitosan layer deposition they become positively charged. The $\zeta$-potential measurement was performed at $\mathrm{pH}=7.0$. All the amino groups belonging to chitosan are protonated at $\mathrm{pH}$ lower than 6.0. The concentration of the surface amino groups was estimated by conductometric titration. It can be seen that there is an obvious rise in zeta potential with the addition of magnetic nanoparticles to chitosan. It is worth noting that magnetite is an amphoteric solid, which can develop charges in the protonation and deprotonation reactions of $\mathrm{Fe}-\mathrm{OH}$ surface sites ${ }^{20}$. The results prove that chitosan-magnetite nanocomposite particles bear surface free amino groups available for functionalization.

Table 3. Surface property

\begin{tabular}{ccc}
\hline & Zeta potential, $\xi, \mathrm{mV}$ & $\mathrm{NH}_{2}$ groups equiv/g \\
\hline Magnetite particles & -3.3 & - \\
chitosan-magnetite & +3.88 & $6.9 \times 10^{-5}$ \\
nanocomposite particles & & \\
\hline
\end{tabular}

$\zeta$-potential measured in $0.2 \mathrm{M}$ phosphate buffer, $\mathrm{pH}=7.0$. Surface amino groups determined by conductometric titration of a concentrated suspension of $\mathrm{pH}=6.0$

\section{Magnetic properties}

The magnetization curves obtained for bare magnetite and composite particles are presented in Figure 1. The magnetic saturation was about $72.2 \mathrm{emu} / \mathrm{g}$ for bare magnetite and around $51.6 \mathrm{emu} / \mathrm{g}$ for chitosan-magnetite nanocomposite particles. The saturation magnetization of around $51.6 \mathrm{emu} / \mathrm{g}$, is higher than those reported in literature for other chitosan based $\mathrm{Fe}_{3} \mathrm{O}_{4}$ beads ${ }^{21,22}$. It can also be observed from this figure that magnetization moment of $\mathrm{Fe}_{3} \mathrm{O}_{4}$ nanoparticles decreases a little after chitosan surface coating. This result signifies that chitosan does not affect magnetic properties of these composite beads, which can be explained by high coating efficiency by chitosan on $\mathrm{Fe}_{3} \mathrm{O}_{4}$ particles. Therefore, maintaining such a high saturation magnetization value after coating these beads is more advantageous and susceptible to the external magnetic field for magnetic separation, compared with those beads that have very low magnetic properties.

\section{Effect of dosage of coagulant}

Coagulation/flocculation processes have been widely used as pre-treatments to remove suspended particles and colouring materials in primary treatment prior to biological treatment. The aim of the coagulation step was to remove turbidity, TSS, oil and COD reduction in order to improve the efficiency of the subsequent treatments. Effect of different coagulant dosage for chitosan-magnetite nanocomposite and chitosan on the destabilization of POME was analyzed. The tests were carried out at original $\mathrm{pH}$ of POME sample, i.e. 4.8. 
The effect of coagulant dosage was analyzed by varying the weight dosage of coagulant (50-2000 $\left.\mathrm{mgL}^{-1}\right)$. Both chitosan and chitosan-magnetite nanocomposite particles, acts as a primary coagulant to destabilize, coagulate and further flocculate the suspension.

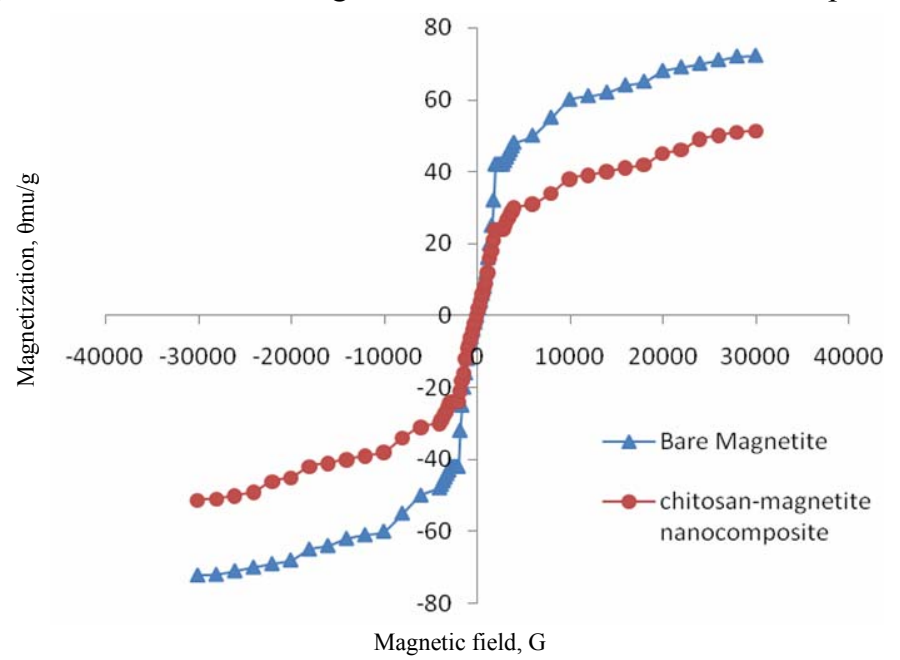

Figure 1. Magnetization curves obtained for bare magnetite and chitosan-magnetite composite particles

The results on residual oil removal efficiency are presented in Figure 2. The figure show that the increases of coagulant dosage, leads to better performances. It was noticed that $280 \mathrm{mg}$ of chitosan-magnetite nanocomposite was needed to remove $99 \%$ of residue oil from a litre of POME. The removal of same amount residue oil from 1 litre POME requires $370 \mathrm{mg}$ of chitosan particles. The result for chitosan is consistent with previous findings ${ }^{13,14}$. Even at very low concentration of $100 \mathrm{mg} / \mathrm{L}$, chitosan-magnetite nanocomposite could remove about $75 \%$ of the residue oil from POME. Surface iron atoms on iron oxide can coordinate with molecules to donate lone-pair electrons, therefore acting as Lewis acids. In aqueous environments the iron oxide is in the form of hydroxyl groups due to the coordination and further dissociation with water. The surface of magnetite can become positive or negative depending on the actual $\mathrm{pH}$ of the solution. Magnetite, a mixed $\mathrm{Fe}^{2+} / \mathrm{Fe}^{3+}$ oxide, has an isoelectric point at $\mathrm{pH}$ 6.5. Consequently, below the isoelectric point, a protonation of the particle surface leads to the formation of $\equiv \mathrm{Fe}-\mathrm{OH}_{2}{ }^{+}$moieties. Deprotonation occurs above the isoelectric point giving rise to $\equiv \mathrm{Fe}-\mathrm{O}^{-}$surface moieties ${ }^{23}$. Magnetite, a mixed $\mathrm{Fe}^{2+} / \mathrm{Fe}^{3+}$ oxide, has an isoelectric point at $\mathrm{pH} 6.5$; the positive charge on the oxide is enhanced under acidic conditions ${ }^{24}$. Chitosan and chitosan-magnetite composite are both positively charged linear polyelectrolyte at acidic conditions. POME is naturally an acidic suspended effluent and could easily stimulate chitosan or chitosan-magnetite composite to coagulate the residue oil from POME. There appears to be an additive effect, almost as though different compounds are removed by the oxide and by the polymer. The amine functional groups in chitosan and the positively charged magnetite (at $\mathrm{pH} 4.8$ ) help to coagulate and adsorb the residue oil which is negatively charged in $\mathrm{POME}^{25}$. When the charges are neutralized, the small suspended particles are capable to interact together through rapid mixing. Once the coagulation process was completed, these positively charged polyelectrolyte adsorbents could generate a 'macroflocs' particles with slow mixing ${ }^{26}$. When the floc reached its optimum size and strength, the wastewater is subjected to the sedimentation process. 


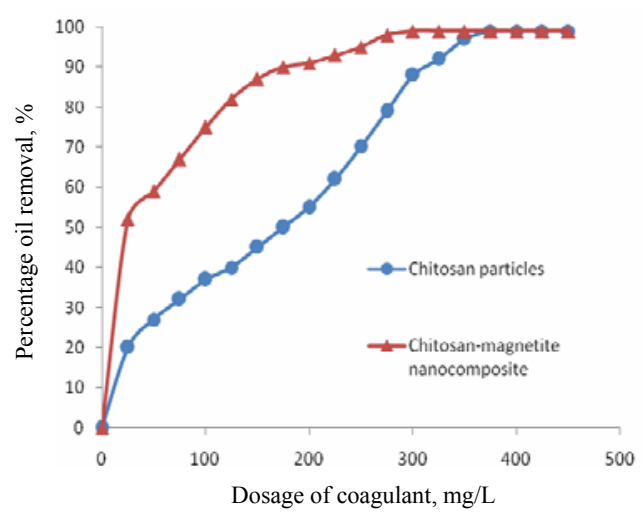

Figure 2. Percentage of residual oil removed with increasing dosage of coagulant

The trends for other parameters are almost identical. Chitosan-magnetite nanocomposite recorded the highest reduction of parameters for the applied dosage of $250 \mathrm{mg} / \mathrm{L}$, which are the reduction of $98.8 \%, 97.6 \%$ and $62.5 \%$ for turbidity, TSS and COD, respectively (Figure 3). On the other hand, chitosan seems to require much higher dosage, i.e. $370 \mathrm{mg} / \mathrm{L}$ to achieve the best turbidity, TSS and COD reductions, which are $97.7 \%, 91.7 \%$ and $42.70 \%$, respectively (Figure 4). Thus, chitosan-magnetite nanocomposite was far better than chitosan for POME coagulation, since it provides better parameter reductions. The results for chitosan are in agreement with the study by Ahmad et al, (2006), which reported that chitosan is a better coagulant even at lower dosage to remove suspended solids of POME, compared to alum and PAC, which needed much higher dosage ${ }^{13}$. For chitosan-magnetite nanocomposite, some previous study had been reported on its use as an adsorbent for removal of heavy metal ions from industrial wastewater. All of them have reported improved adsorption by chitosan-magnetite nanocomposite as compared with chitosan ${ }^{27-29}$.

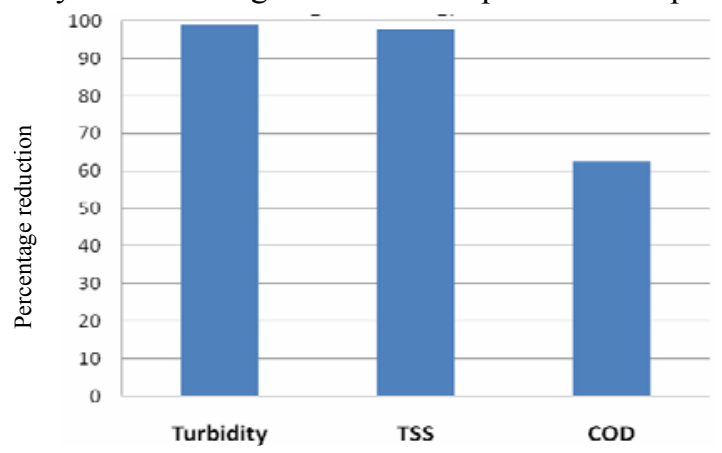

Figure 3. Highest percentage removal of turbidity, TSS and COD using chitosanmagnetite nanocomposite as coagulant at dosage of $250 \mathrm{mg} / \mathrm{L}$

This phenomenon could be explained based on charge density. Polymer adsorption increased as the charge density of the polymer increased ${ }^{30}$. Chitosan has a high charge density compared to the other coagulants ${ }^{13}$. Therefore, this signifies the rapid destabilization of the particles and can also be concluded that the amount of the coagulant required to destabilize the particles is less for a coagulant of higher charge density, i.e. chitosanmagnetite nanocomposite. In acid solution the both the amino groups of chitosan and the magnetite particle are protonated. The chitosan- magnetite nanocomposite in acidic solution 
becomes highly positively charged and hence allowing the molecule to bind to negatively charged surface via ionic or hydrogen bonding. This will further reduce or neutralize the particles surface charge. Therefore, the particles destabilization by chitosan-magnetite nanocomposite could be explained by charge neutralization mechanism.

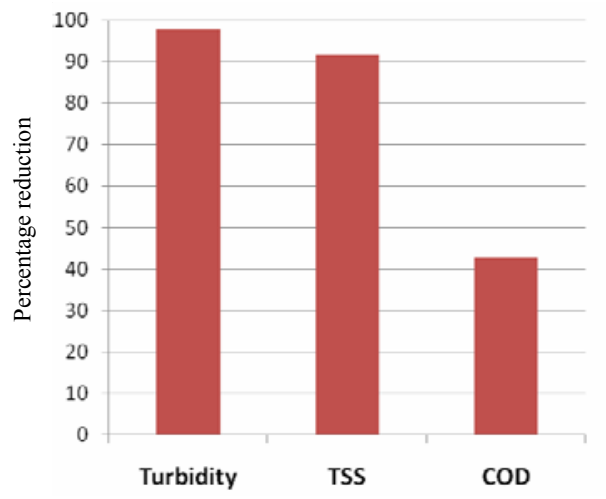

Figure 4. Highest percentage removal of turbidity, TSS and COD using chitosanparticles as coagulant at dosage of $370 \mathrm{mg} / \mathrm{L}$

However, overdosing of coagulant (chitosan magnetite nanocomposite or chitosan) beyond the optimal state causes a slight decrease in the removal efficiencies. This could be due to reversal of surface charge as well as the restabilization of coagulated particles. Once the chitosan-magnetite nanocomposite or chitosan dosage exceeds the saturation of polymer bridging, surplus chitosan-magnetite nanocomposite or chitosan has a tendency to destroy the polymer bridging between particles, thereby exhibiting an increase in residual turbidity.

\section{Effect of $\mathrm{pH}$ on chitosan performance}

The study of $\mathrm{pH}$ is essential to determine the optimum $\mathrm{pH}$ condition of a treatment system. The $\mathrm{pH}$ will not only affect the surface charge of coagulants, but also affects the stabilization of the suspension. The effect of $\mathrm{pH}$ was conducted by adjusting the $\mathrm{pH}$ from 3 to 8 and using the optimum dosage of chitosan- magnetite nanocomposite and chitosan with $30 \mathrm{~min}$ of mixing time and $100 \mathrm{rpm}$ of mixing rate. The sample was then let to settle for $1 \mathrm{~h}$. The parameter reductions for chitosan-magnetite nanocomposite and chitosan coagulation at different $\mathrm{pH}$ are shown in Figure 5. Nearly 97\% of removal could be achieved at this initial $\mathrm{pH}$ of 3. Both the coagulants showed a good potential of residue oil removal at initial $\mathrm{pH}$ value. This situation is believed to create more possibility for particles restabilization due to reversal of surface charge, compared to at a higher $\mathrm{pH}$. It is known that strong acidic led to very strong cationic charge on chitosan as well as on the magnetite particle ${ }^{31}$. A synergistic effect of magnetite-polyelectrolyte combination achieved higher percentage removal of the contaminants. These percentage of removal remained up to the $\mathrm{pH}$ of 4.0. When the $\mathrm{pH}$ was adjusted to a higher value to about $\mathrm{pH} 5$ and above, the residue oil removal was poorer compared to the acidic condition. The percentage removal of residual oil did not dropped for chitosan-magnetite nanocomposite up to $\mathrm{pH} 5$ but for chitosan the removal percentage was $78 \%$. The acidic condition of POME incites the residue oil removal. Strong acidic condition aggravates POME to break oil droplets and destabilization of suspended solid in the suspension. Thus, enhances the coagulation of residue oil in POME. Therefore, the electrostatic attractions between residue oil molecules and adsorption site increase and indirectly increase the adsorption of residue oil. 


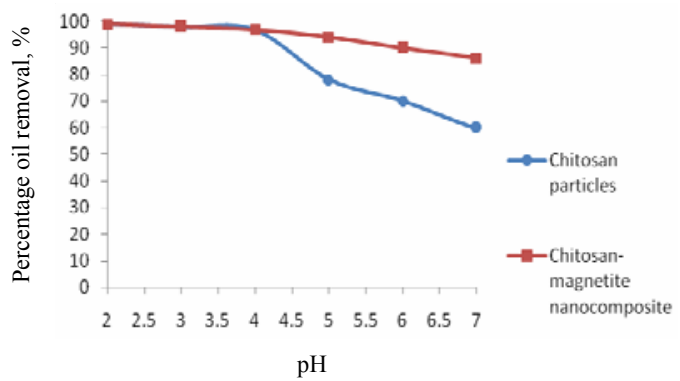

Figure 5. Effect of $\mathrm{pH}$ on percentage removal of residual oil using chitosan particles and chitosan magnetite nanocomposite

The trends for all parameters are almost identical. The Figure 5 demonstrates that over $99 \%$ turbidity reduction can be achieved at $\mathrm{pH} 3$ to 6.0 ; of these the optimum is $\mathrm{pH} 4.5$. At $\mathrm{pH} 4.5$, the removal of turbidity, TSS and COD were $99.90 \%, 99.15 \%$ and $60.73 \%$, respectively. Therefore, chitosan-magnetite nanocomposite demonstrates the best result of POME destabilization in acidic condition, while portrays poorer efficiencies in neutral and alkaline condition. The suspended solid value of POME was higher at $\mathrm{pH} 3$ compared to the one at $\mathrm{pH} 4.5$. This shows the destabilization of suspended solid in acidic condition. At pH more than 5.0 the turbidity TSS and COD value was higher and increased steadily for both the coagulant. When the $\mathrm{pH}$ value was more than $\mathrm{pH} 5$ it leads to dissolution of precipitate formed, which indirectly introduces the turbid and increases the suspended solid values ${ }^{32}$. The $\mathrm{pH} 6$ showed the poorest removal efficiency for the coagulant proposed. This may due to the destabilization of the coagulant itself at weaker acid conditions.

\section{Conclusion}

As a conclusion we could say that chitosan-magnetite nanocomposite performed well to coagulant and remove the suspended solid and residue oil from POME compared to chitosan. In comparing with alum (aluminium sulphate) and PAC (polyaluminum chloride) as coagulant from other studies, it is interesting to note that both chitosan-magnetite nanocomposite and chitosan performed exceptionally well to coagulant and remove the suspended solid and residue oil from $\mathrm{POME}^{13,32,33}$. At $\mathrm{pH} 6$, the optimum chitosan-magnetite dosage of $250 \mathrm{mg} / \mathrm{L}$ was able to reduce turbidity, TSS and COD levels by $98.8 \%, 97.6 \%$ and $62.5 \%$ respectively. On the other hand, chitosan seems to require much higher dosage, i.e. $370 \mathrm{mg} / \mathrm{L}$ to achieve the best turbidity, TSS and COD reductions, which were $97.7 \%, 91.7 \%$ and $42.70 \%$, respectively. It was reported earlier that charge neutralization plays an important part for POME destabilization at $\mathrm{pH} 4.5$. Domard et al. (1989) pointed out that there are $90 \%$ of the functional group of $\mathrm{NH}_{2}$ on chitosan surface has been protonated at $\mathrm{pH} 4$ and gradually reduced to about $50 \%$ as $\mathrm{pH}$ increased to $6^{34}$. Roussy et al. (2005) also proved that chitosan at alkaline $\mathrm{pH}$ (i.e. $\mathrm{pH}$ 8.5) shows very low efficiency and required high concentration of chitosan to achieve the required treatment levels. This confirmed that, at least partial protonation of chitosan amino group as well as the magnetite ion was required to achieve efficient coagulation of these organic suspensions ${ }^{35}$. The synergistic effect of cationic character of both the chitosan amino group and the magnetite ion in the pre-treatment process for POME brings about enhanced performance for effective agglomeration, adsorption and coagulation and flocculation. The results showed that coagulation with chitosan-magnetite or chitosan were an effective and environmentally friendly pre-treatment technique for palm oil mill effluent wastewater compared to alum and PAC which creates hazardous residual waste.

\section{Acknowledgement}

The authors gratefully acknowledge the research grant (J510050316) from Research Management Centre (RMC), Universiti Tenaga Nasional, Malaysia. 


\section{References}

1. Vijayaraghavan K, Ahmad D and Abdul Aziz M E B, J Environ Manage., 2007, 82, 24-31.

2. MPOB, (2009). Summary of industry performance: 2009. http://econ.mpob.gov.my/economy/EID_web.htm (accessed January 2010).

3. Yusoff S, J Cleaner Production, 2006, 14(1), 87-93.

4. Ma A N, Cheah S C and Chow M C, Current status of palm oil processing wastes management, Waste Management in Malaysia: Current Status and Prospects for Bioremediation, 1993, 111-136.

5. Choo Y M, Malaysian Oil Sci Tech., 2007, 16, 12-20.

6. $\quad$ Ma A N and Ong A S H, Biol Wastes., 1988, 23, 85-97.

7. Yacob S, Hassan M A, Shirai Y, Wakisaka M and Subash S, Chemosphere, 2005, 59, $1575-1581$.

8. Government of Malaysia (1977). Environmental Quality (Prescribed Premises), (Crude Palm Oil) Regulations 1977. P.U.(A) 342/1977, amended by P.U.(A) 183/82.

9. Nik Norulaini N.A, Ahmad Zuhairi A, Muhamad Hakimi I and Mohd Omar A K, $J$ Ind Technol., 2001, 10(1), 55-72.

10. Selmer-Olsen E, Ratnaweera H and Pehrson R Water Sci Technol., 1996, 34(11), 33-40.

11. Meyssami B and Kasaeian A B, Bioresour Technol., 2005, 96, 303-307.

12. Sakkayawong N, Thiravetyan P and Nakbanpote W, J Colloid Interf Sci., 2005, 286, 36- 42.

13. Ahmad A L, Sumathi S and Hameed B H, Chem Eng J., 2006, 118(1-2), 99-105.

14. Savant V D and Torres J A, Biotechnology Progress, 2000, 16, 1091-1097.

15 Cheng W P, Chi F H, Yu R F and Lee Y C, J Poly Environ., 2005, 13(4), 383-388.

16. Shena Y F, Tang J, Nie Z H, Wang Y D, Ren Y and Zuo L, Sep Purif Technol., 2009, 68, 312-319.

17. Liu X W, Hu Q Y, Fang Z, Zhang X J and Zhang B B, Langmuir, 2009, 25, 3-8.

18. Hong M K, Park B J and Choi H J, Phys Stat Sol (a), 2007, 204(12), 4182-4185

19. APHA AWWA WPCF, (1992). Standard Methods for Examination of Water and Wastewater. $18^{\text {th }}$ Ed., Washington, DC, 1992.

20. Hajdú A, Illés E, Tombácz E and Borbáth I, Colloids Surf A: Physicochem Eng Aspects, 2009, 347(1-3), 104-108.

21. Zhou Y T, Nie H L, Branford-White C, He Z Y and Zhu L M, J Colloid Interf Sci., 2009, 330(1), 29-37.

22. Ma Z Y, Guan Y P and Liu H Z, J Polym Sci Par A Polym Chem., 2005, 43(15), 3433.

23. Laurent S, Forge D, Port M, Roch A, Robic C and Vander Elst L, Chem Rev., 2008, 108:2064-2110.

24. Kolarik L. O, Water Res., 1983, 17, 141-147.

25. Jill R P, Chihpin H, Shuchuan C and Ying-Chien C, Colloids Surf., 1999, 147, 359-364.

26. Boisvert J P, To T C, Berrak A and Julicocur C, Water Res., 1997, 31, 1937-1946.

27. Chang CY, Chang S W and Chen D H, React Function Poly., 2006, 66, 335-341

28. Qi L and Xu Z, Colloids Surf A, 2004, 251, 186-193.

29. Donia A M, Atia A A and Elwakeel K Z, J Hazard Mater., 2008, 151, 372-379.

30. Ariffin A, Shatat R S A, Nik Norulaini A R and Mohd Omar A K, Desalination, 2005, 173(3), 201-208.

31. Ashmore M and Hearn J, Langmuir, 2000, 16, 4906-4911.

32. Pinotti A and Zaritzky N, Waste Manage., 2001, 21, 535-542.

33. Kevin M, Kenneth C and Dean G, Water Res., 2004, 38, 486-494.

34. Domard A, Rinaudo M and Terrassin C, J Appl Poly Sci., 1989, 38, 1799-1806.

35. Roussy J, Vooren M V, Dempsey B A and Guibal E, Water Res., 2005, 39, 3247-3258. 


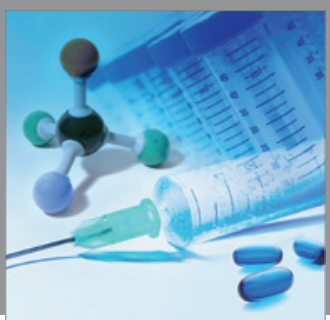

International Journal of

Medicinal Chemistry

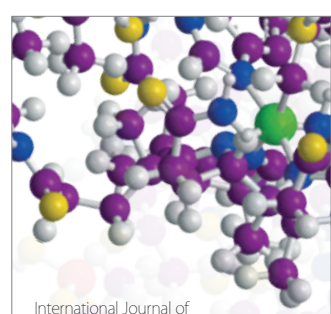

Carbohydrate Chemistry

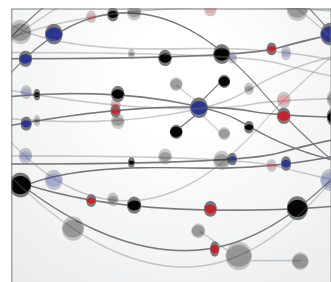

The Scientific World Journal
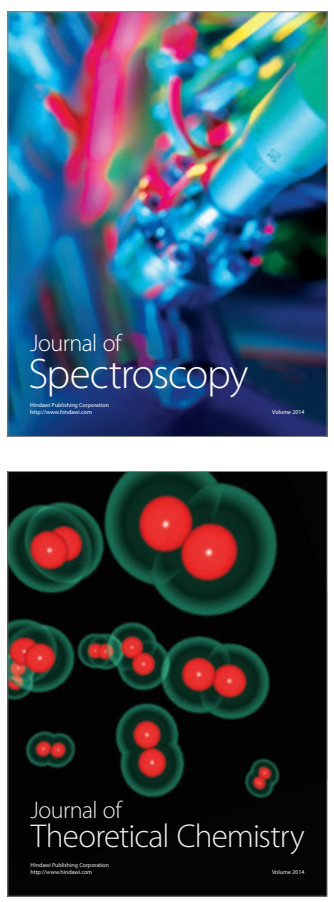
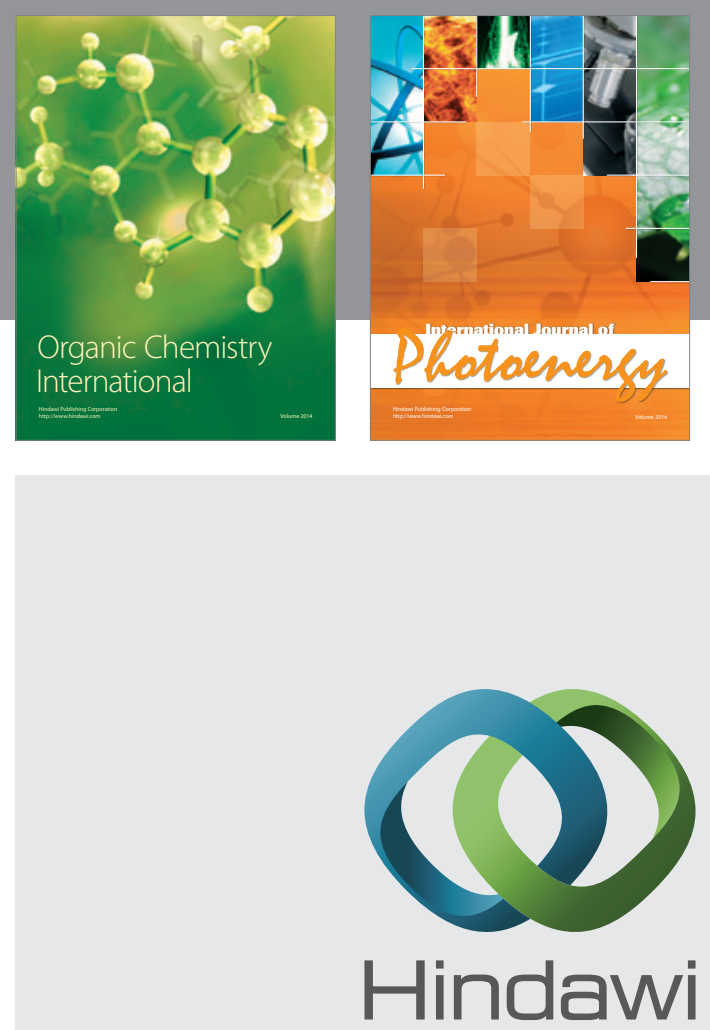

Submit your manuscripts at

http://www.hindawi.com
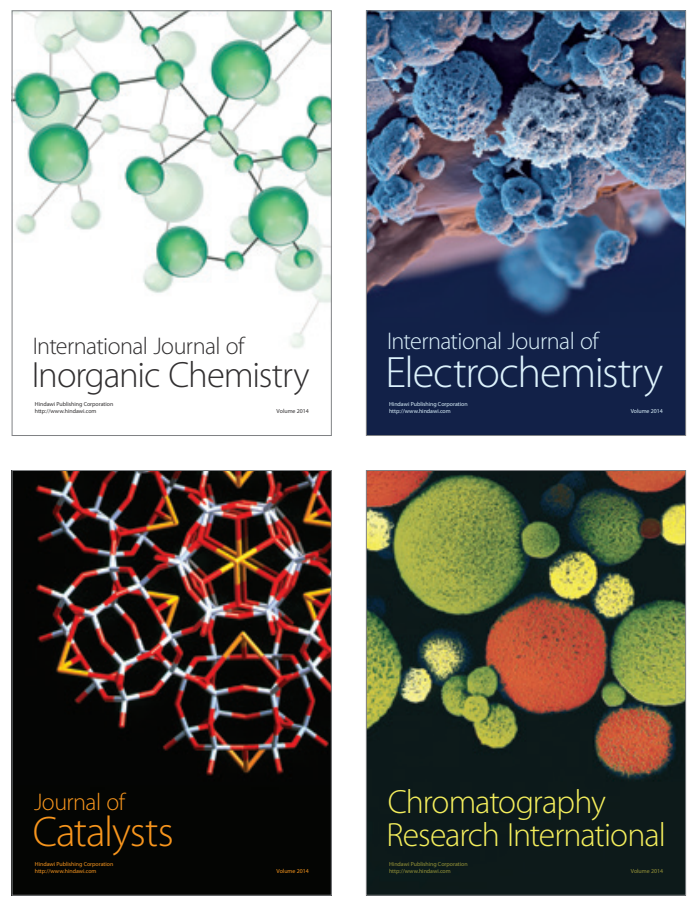
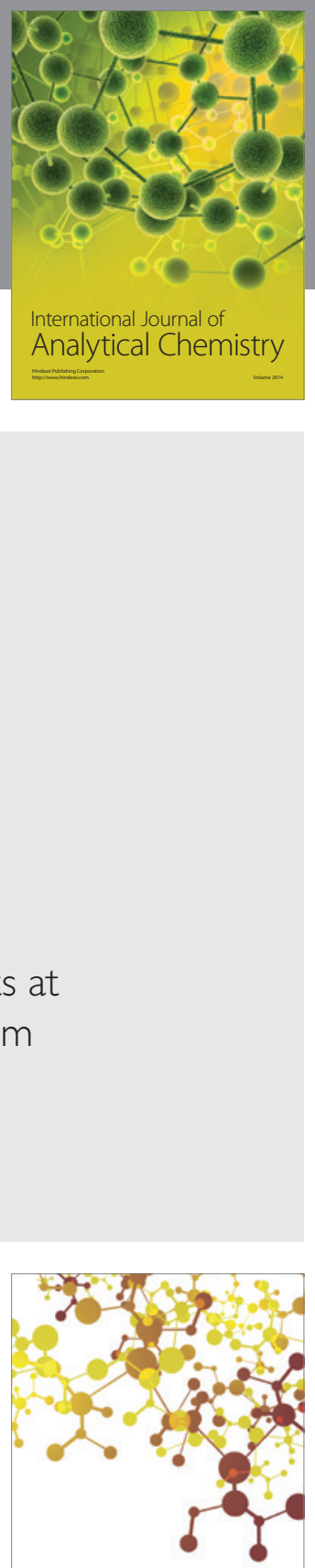

Journal of

Applied Chemistry
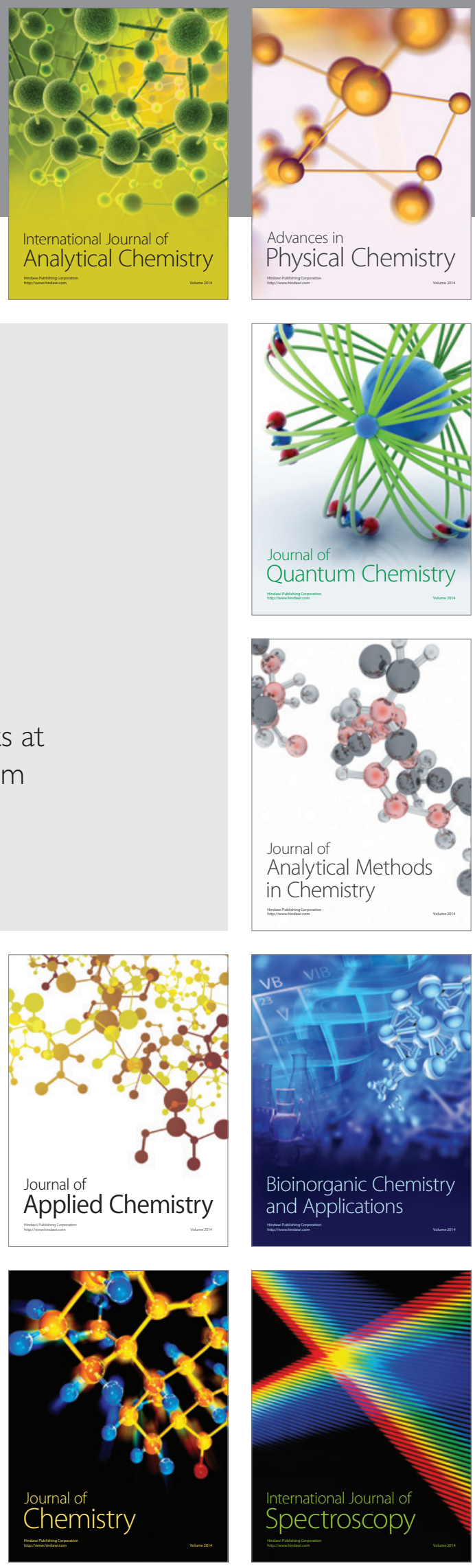